\title{
RESPONSE SENSITIVITY OF THE STRUCTURE USING VIBRATION BASED DAMAGE DETECTION TECHNIQUES
}

\author{
Pooja $\mathbf{K}^{1}$, Siddesha $\mathbf{H}^{2}$, Manjunath $\mathbf{N}$ Hegde $^{3}$ \\ ${ }^{1}$ Post Graduate Student, ${ }^{2}$ Assistant Professor, Department of Civil Engineering, Siddaganga Institute of \\ Technology, Tumkur \\ ${ }^{3}$ Professor, Department of Civil Engineering, Ambedkar Institute of Technology, Tumkur \\ poojakdev29@gmail.com,siddeshah@gmail.com,mmmhegde@gmail.com
}

\begin{abstract}
Many developments have been carried out in order to try to quantify the effects produced by damage and the vibration based methods of damage diagnostics are proved to be promising. In the present study, a two storey one bay steel portal frame with cross bracing is considered as an undamaged case. The damage is introduced to the frame by removing the bracing at various levels. The modal parameters of the undamaged and damaged frames were extracted by using FEM software ANSYS 14.5 and validated through experimental results performed using mini shake table. The Frequency response function $(F R F)$ plot is drawn from the experimental results. Further the damage is introduced to the frame by reducing the young's modulus, reducing the cross sectional area and increasing the temperature due to fire in bracing and at each floor is also studied by using ANSYS 14.5 by performing the modal analysis. The results show that the natural frequencies for the damaged structure decreases and the amplitude increases.
\end{abstract}

Keywords: steel frame structure, damage detection, sensitivity analysis, Dynamic response, fire temperature.

\section{INTRODUCTION}

The structural damage detection and identification is a vital part of the monitoring and servicing of structural systems during their lifetime. The term damage does not necessarily imply a total loss of system functionality, but rather that the system is no longer operating in its optimal manner. Structural damage in normal service may include fatigue, aging/long term environmental attach leading to corrosion of steel, or it may be caused by fire, earthquake. This will result in the degradation of structural elements and reduction in structural stiffness and strength.

Sadettin Orhan [1] performed free and forced vibration of a cantilever beam using ANSYS finite element program to obtain change in natural frequencies and harmonic responses corresponding to the change in crack depth and location for crack detection. Usik Lee et.al [2] Existence of structural damages within a structure leads to the changes in dynamic characteristics of the structure such as the vibration responses, natural frequencies, mode shapes, and the modal damping. Therefore, the changes in dynamic characteristics of a structure can be used in turn to detect, locate and quantify the structural damages generated within the structure. Songtao et.al [3] considered the natural frequency of a structure as a constant value except for the existence of damages caused by impact, operating loads, fatigue or other similar factors. Moreover, natural frequency can be easily and cheaply obtained from measured vibration responses. So, structural health monitoring (SHM) by studying the changing of natural frequency becomes a popular way to identify the damages of a structure and the basis of repairing, rehabilitating or replacing a structure. N. Banora et.al [4] proposed that use of damage models require a number of material parameters the identification of which should be made, when possible, based on direct measures of the damage that develops in the material. Among the possible experimental techniques to measure the occurrence of ductile damage in metals, the measure of the damage through the degradation of the material Young's modulus has been indicated as one of the more effective technique and used by several authors.N.M.M. Maia et.al [5] presented a numerical analysis using ANSYS along with experimental work for damage detection using mode shape changes and FRF- based methods. H.Y. Hwang et.al [6] presented a method to identify the location and severity of damage in structures using frequency response function (FRF) data. D.P. Patil et.al [7] gave a method for prediction of location and size of multiple cracks based on measurement of natural frequencies and was verified experimentally for slender cantilever beams with two and three normal edge cracks. X. Liu et.al [8] used frequency response function (FRF) shapes for structural damage localization.

In this paper, the essential principle is to compare the structural behaviour in the damaged and undamaged states. The problem considered here is a cross braced two storey steel portal frame and a FEM (ANSYS) Analysis is used to find the modal parameters of the frame. Then the different damage 
cases when the bracings of the frame are removed are considered and Analysis is repeated on the same and t3he variation of the modal parameters is studied for undamaged and different damaged cases and the same is verified using experimental Technique.

Further different causes of damage such as reduction in cross sectional area, reduction of young's modulus (E), and rise in temperature due to fire which leads to deterioration of the structural members in a structure are studied and damage is detected using FEM (ANSYS) Analysis. From the results obtained change in natural frequencies are tabulated and frequency response function are plotted.

\section{EXPERIMENTAL WORK}

A one bay two storey portal frame is fabricated. The flat steel bars having a width of $10 \mathrm{~mm}$ are welded together to form the frame. The thickness of column and bracing, bottom beam and top beam is $3 \mathrm{~mm}$ and $20 \mathrm{~mm}$ respectively. The Density of the steel bars is $7850 \mathrm{Kg} / \mathrm{m} 3$ and Modulus of Elasticity is 200 Gpa. The total height of the frame is $600 \mathrm{~mm}(300 \mathrm{~mm}$ each floor) and the total width being $275 \mathrm{~mm}$. The model is welded at the bottom to the plate with four holes to provide fixity and through which it is bolted to a mini shake table.

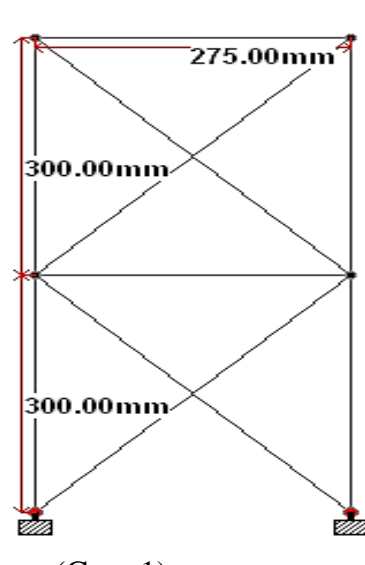

(Case 1)

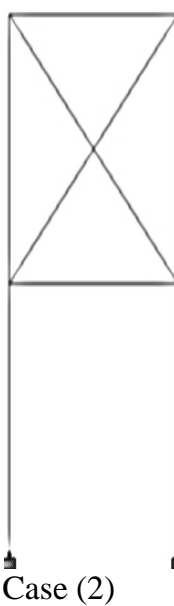

Case (2)
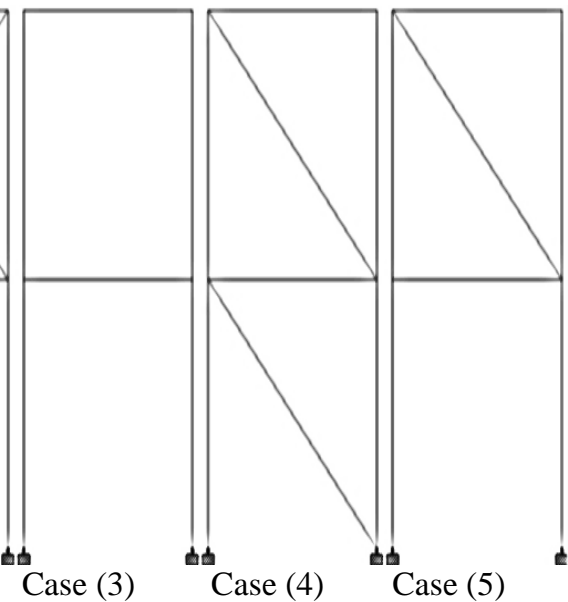

Fig.1 Steel Frame with Full X Bracing

Fig.2 Damaged Configurations of the Steel Frame

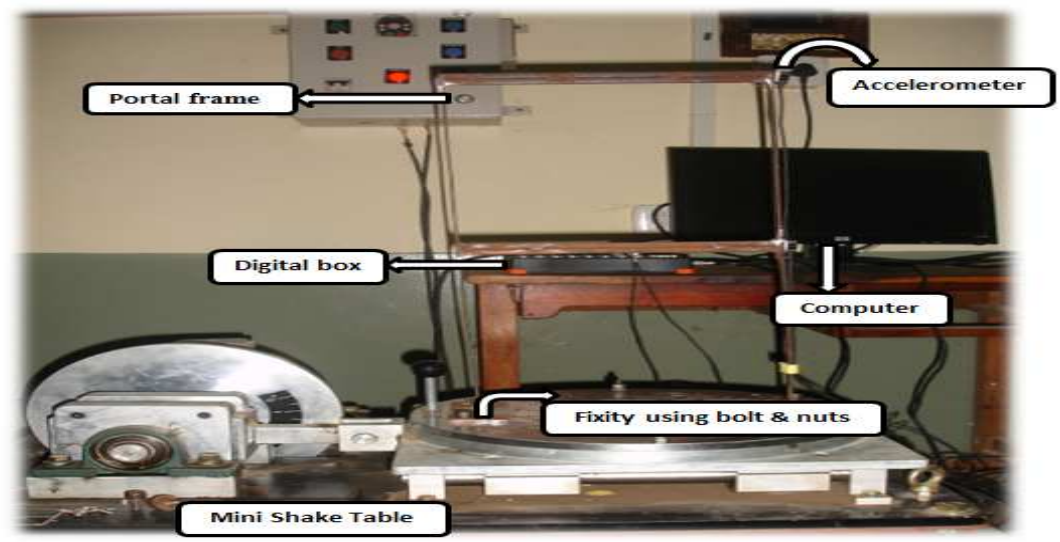

Fig.3 Typical Sketch showing the accelerometers connected to steel frame in mini shake table

\subsection{Free Vibration Test Results}

The sinusoidal graphs of displacement versus time obtained from the Free Vibration Test for different frame are as shown below: 


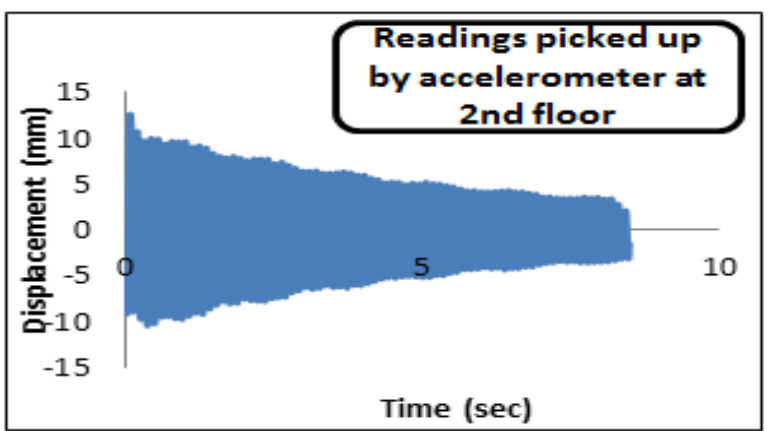

Fig.4 First floor displacement details from Free vibration test for case (5)

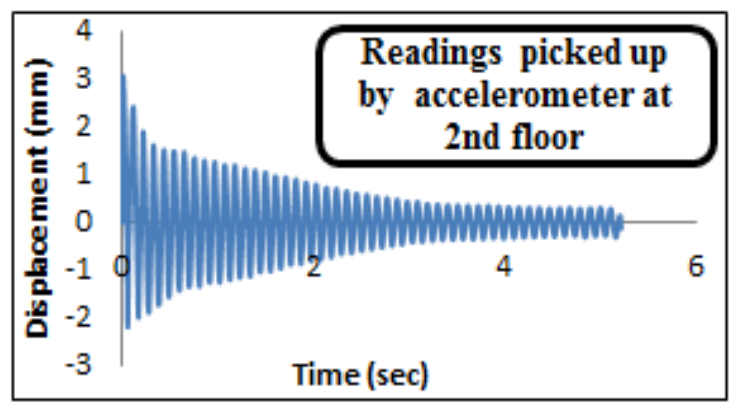

Fig.5. First floor displacement details from free vibration test for case (3)

From the results of Table 1 it is observed that the damping ratio for a damaged frame is less when compared to an undamaged frame which means that the damaged frame takes longer time to stop vibrating than the undamaged frame. That is because when a bracing is removed from a frame the stiffness of the frame decreases and thus it takes longer time to come back to its original position once it is vibrated.

\subsection{Experimental Validation}

Table 2 comparison of the Results obtained from ANSYS and Experiment

\begin{tabular}{|l|l|l|l|}
\hline \multirow{2}{*}{$\begin{array}{l}\text { Frame } \\
\text { type }\end{array}$} & \multicolumn{4}{|l|}{ First Natural Frequency in $\mathrm{Hz}$} \\
\cline { 2 - 4 } & $\begin{array}{l}\text { From } \\
\text { ANSYS }\end{array}$ & $\begin{array}{l}\text { From } \\
\text { Experiment }\end{array}$ & \% diff \\
\hline case(3) & 8.9 & 8.852 & 0.54 \\
\hline $\operatorname{case}(5)$ & 8.46 & 8.335 & 1.49 \\
\hline $\operatorname{case}(2)$ & 7.79 & 7.692 & 1.27 \\
\hline
\end{tabular}

From Table 2 it is observed that there is no much difference between the values obtained from experiment and ANSYS.

\subsection{Forced Vibration Test}

In Forced vibration test an external forcing frequency is applied to the frame with the help of the horizontal shake table. The forcing frequency is from $2 \mathrm{~Hz}$ to $10 \mathrm{~Hz}$ and with the increment of $0.2 \mathrm{~Hz}$. At every increment of the forcing frequency, the readings are noted down from the DEWESoft software. The graphs of acceleration versus forcing frequency are plotted. The graphs obtained from the Force Vibration Test are as shown in Fig.7 and Fig.8. 


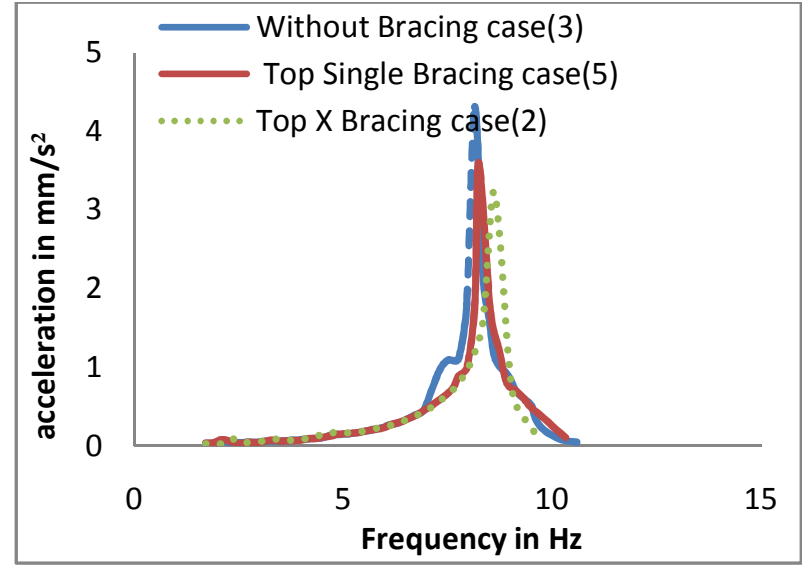

Fig.7 Frequency versus acceleration details of First floor for different damage configurations

From the Figure 7 and 8 it is observed that with the removal of damaged bracing there is a decrease in frequency and increase in displacement and it is observed that Reduction of frequency is from $3.5 \%$ to $5 \%$ whereas increase in amplitude varies from $8 \%$ to $20 \%$. The response for case (1) and case (4) could not be obtained because for full bracings at top and bottom the stiffness is more and hence amplitude is very less which could not be picked up.

\section{NUMERICAL ANALYSIS}

The ANSYS 14.5 finite element program [12] was used for analysis and the structure was modeled using the Beam 2 node 188 element. For different damage scenario the changes in first five natural frequencies are tabulated.

\subsection{Damage Due To Removal of Bracing}

Damage due to removal of bracing may be due to accumulation of damage at the joints that leads to disconnectivity at the joint. Hence in the present study bracings are removed at different levels to study changes in natural frequency due to the damage which are shown in the Table 3 .

Table 3 Comparison of natural frequencies for undamaged and different damaged cases

\begin{tabular}{|l|l|l|l|l|l|}
\hline \multirow{2}{*}{$\begin{array}{l}\text { Mode } \\
\text { No }\end{array}$} & \multicolumn{4}{|l|}{ Natural Frequency in $\mathrm{Hz}$} \\
\cline { 2 - 6 } & $\begin{array}{l}\text { Case } \\
(1)\end{array}$ & $\begin{array}{l}\text { Case } \\
(2)\end{array}$ & $\begin{array}{l}\text { Case } \\
(3)\end{array}$ & $\begin{array}{l}\text { Case } \\
(4)\end{array}$ & $\begin{array}{l}\text { Case } \\
(5)\end{array}$ \\
\hline 1 & 8.92 & 8.9 & 7.56 & 8.46 & 8.04 \\
\hline 2 & 40 & 37.58 & 37.8 & 38.9 & 38.1 \\
\hline 3 & 54.9 & 52.55 & 51.7 & 53.1 & 51 \\
\hline
\end{tabular}

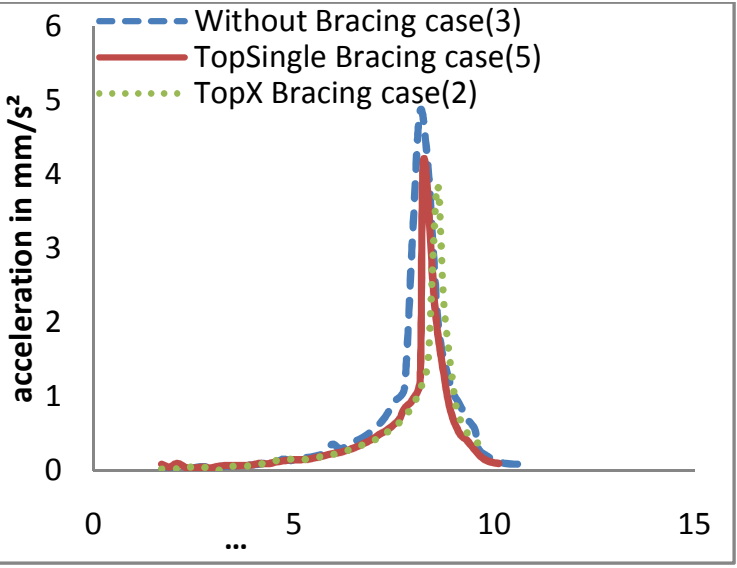

Fig.8. Frequency versus acceleration details of second floor for different damage configurations

\begin{tabular}{|l|l|l|l|l|l|}
4 & 94 & 94.01 & 93.6 & 93.2 & 92.2 \\
\hline 5 & 106 & 105.7 & 103 & 98.8 & 101 \\
\hline
\end{tabular}

From the Table 3 it is observed that the frequencies of different damaged cases reduce when compared to undamaged case. This is because removal of damaged bracing in the frame causes damage to the structure due to which there is reduction of stiffness which in turn leads to the reduction of frequencies.

\subsection{Damage Due to Reduction Of 25, 50 And $75 \%$ of} Young's Modulus in Bracings

Due to damage the load carrying capacity of the structure may decrease that causes change in the stress-strain curve. Hence to study the ductile damage the reduction of young's modulus of 25,50 and $75 \%$ in the bracings is considered for study and the natural frequencies obtained using ANSYS Software are shown in the Table 4.

Table 4 Natural Frequencies of undamaged frame when there is reduction of $\mathrm{E}$

\begin{tabular}{|c|c|c|c|c|}
\hline \multirow{2}{*}{$\begin{array}{c}\text { Mode } \\
\text { No }\end{array}$} & \multicolumn{4}{|c|}{ Natural Frequencies in $\mathrm{Hz}$} \\
\hline & $\begin{array}{l}\text { Case } \\
\text { (1) }\end{array}$ & $25 \%$ & $50 \%$ & $75 \%$ \\
\hline 1 & 8.892 & 8.67 & 8.47 & 8.26 \\
\hline 2 & 40.03 & 39.62 & 39.20 & 38.74 \\
\hline 3 & 54.92 & 54.09 & 52.21 & 47.02 \\
\hline 4 & 94.01 & 70.39 & 68.20 & 65.04 \\
\hline 5 & 106.2 & 105.3 & 104.6 & 102.1 \\
\hline
\end{tabular}


The Table 4 show that when there is damage due to reduction of young's modulus in bracings the frequency reduces this is because of reduction in stiffness which causes damage.

\subsection{Damage Due To Reduction Of 25, 50 And $75 \%$ Of}

\section{Cross Sectional Area In Bracings}

When the structure is consistently exposed to an aggressive environment it may cause corrosion due to which there may be reduction of cross sectional area. Hence to study the damage the reduction of cross sectional area of 25,50 and $75 \%$ in the bracings is considered for study using ANSYS Software and the results are shown in the Table 5.

Table 5 Natural Frequencies of undamaged frame when there is reduction of $\mathrm{A}$

\begin{tabular}{|l|l|l|l|l|}
\hline \multirow{2}{*}{ Mode No } & \multicolumn{4}{|l}{ Natural Frequencies in $\mathrm{Hz}$} \\
\cline { 2 - 5 } & $\begin{array}{l}\text { Case } \\
(1)\end{array}$ & $25 \%$ & $50 \%$ & $75 \%$ \\
\hline 1 & 8.892 & 8.55 & 8.20 & 7.83 \\
\hline 2 & 40.03 & 38.92 & 37.74 & 36.4 \\
\hline 3 & 54.92 & 52.91 & 50.73 & 46.9 \\
\hline 4 & 94.01 & 81.10 & 66.32 & 48.3 \\
\hline 5 & 106.2 & 104 & 101.49 & 97.6 \\
\hline
\end{tabular}

From the Table 5 it is observed that there is reduction of frequency when there is damage caused due to reduction of cross sectional area in bracings.

\subsection{Damage Due To Fire}

Fire will cause rise in temperature which reduces the strength and young's modulus and hence deterioration takes place. In the present study we are checking the sustainability of the building in case of fire which might cause rise in temperature between $600^{\circ} \mathrm{C}-800^{\circ} \mathrm{C}$

\subsubsection{Damage Due To Fire When There Is Rise In}

\section{Temperature In The Bracings}

Table 6 Natural Frequencies of undamaged frame when there is rise in temperature

\begin{tabular}{|c|c|c|c|c|}
\hline \multirow[b]{2}{*}{$\begin{array}{l}\text { Mode } \\
\text { No }\end{array}$} & \multicolumn{4}{|c|}{ Natural Frequencies in $\mathrm{Hz}$} \\
\hline & $\begin{array}{l}\text { Case } \\
\text { (1) }\end{array}$ & $600^{\circ} \mathrm{C}$ & $700^{\circ} \mathrm{C}$ & $800^{\circ} \mathrm{C}$ \\
\hline 1 & 8.89 & 8.20 & 7.98 & 7.756 \\
\hline 2 & 40.03 & 37.75 & 37.0 & 36.20 \\
\hline 3 & 54.92 & 50.76 & 49.34 & 42.07 \\
\hline 4 & 94.01 & 66.57 & 55.79 & 47.77 \\
\hline 5 & 106.2 & 101.5 & 99.59 & 96.19 \\
\hline
\end{tabular}

From the Table 6 it is observed that there is reduction of frequency when there is damage caused by rise in temperature due to fire which causes reduction of young's modulus and in turn reduction in stiffness of the member.

\subsubsection{Damage Due To Rise In Temperature When}

\section{There Is Fire On Top Floor (All The Five Members)}

\section{And The Bottom Floor (All The Five Members) Of}

\section{The Frame.}

Table 7 Natural Frequencies of undamaged frame when there is rise in temperature

\begin{tabular}{|l|l|l|l|l|}
\hline \multirow{2}{*}{ Mode No } & \multicolumn{4}{|l|}{ Natural Frequencies in $\mathrm{Hz}$} \\
\cline { 2 - 5 } & $\begin{array}{l}\text { Case } \\
(1)\end{array}$ & $600 \mathrm{oC}$ & $700 \mathrm{oC}$ & $800 \mathrm{oC}$ \\
\hline 1 & 8.892 & 8.360 & 8.090 & 7.60 \\
\hline 2 & 40.03 & 34.41 & 31.88 & 27.9 \\
\hline 3 & 54.92 & 42.95 & 39.45 & 35.1 \\
\hline 4 & 94.01 & 59.78 & 51.65 & 42.0 \\
\hline 5 & 106.2 & 93.98 & 74.81 & 69.3 \\
\hline
\end{tabular}

Table 8 Frequencies of undamaged frame when there is rise in temperature

\begin{tabular}{|c|c|c|c|c|}
\hline \multirow{2}{*}{$\begin{array}{l}\text { Mode } \\
\text { No }\end{array}$} & \multicolumn{4}{|c|}{ Natural Frequencies in $\mathrm{Hz}$} \\
\hline & $\begin{array}{l}\text { Case } \\
\text { (1) }\end{array}$ & $600 \mathrm{oC}$ & $700 \mathrm{oC}$ & $800 \circ \mathrm{C}$ \\
\hline 1 & 8.89 & 5.823 & 5.05 & 4.125 \\
\hline 2 & 40.03 & 27.48 & 24.13 & 19.98 \\
\hline 3 & 54.92 & 41.87 & 37.67 & 31.98 \\
\hline 4 & 94.01 & 59.92 & 51.69 & 41.98 \\
\hline 5 & 106.2 & 93.07 & 91.35 & 77.32 \\
\hline
\end{tabular}

From Table 7 and 8 it is observed that there is reduction of frequency when there is rise in temperature due to fire and it is seen that there is more reduction in case of fire on the ground floor when compared to fire in the top floor. 


\section{CONCLUSIONS}

In the present study, after obtaining the results of two storey steel portal frames from experiment using mini shake table and numerical analysis using ANSYS software, the following conclusions can be drawn:

- There is no much variation of natural frequencies obtained from experiment and ANSYS software.

- Due to removal of the bracing the value of natural frequencies decreases. As the more number of bracings are removed the reduction in the natural frequencies was more.

- The Frequency response function (FRF) shows that due to removal of bracings there is increase in the amplitude.

- Frequency response function (FRF) shows that the variation in amplitude is a better measure to indicate damage in the structure as the variation in amplitude is more when compared to variation in frequencies.

- The natural frequency of the damaged frame is less when compared to the undamaged frame.

- The damage due to rise in temperature in ground floor is more when compared to rise in temperature in the first floor.

- The order of the sensitivity of various damage cases is as follows; The damage due to removal of bracing, damage due to fire that causes rise in the temperature, the damage due to reduction of young's modulus and then the damage due to reduction in cross sectional area.

\section{REFERENCES}

[1] Sadettin Orhan (2007). "Analysis of free and forced vibration of a cracked cantilever beam". $N D T \& E$ International.40: pp. 443-450.

[2] Usik Lee, Jinho Shin (2002).“A frequency response function-based structural damage identification method". Computers and Structures. 80: pp.117-132.

[3] Songtao Xue, Hesheng Tang, Jun Okada1, Toshimitsu Hayashi1, Gang Zong and Satoshi Arikawa (2009). "Natural frequency changes for damaged and reinforced real structure in comparison with shake table and simulation". Materials forum. .33:pp.344-350.

[4] N. Bonora, A. Ruggiero, D. Gentile and S. De Meo (2010). "Practical applicability and limitations of the elastic modulus degradation technique for damage measurements in ductile metals". An International Journal of Engineering Mechanics.pp.1-14.

[5] N. M. M. Maia, J. M. M. Silva, E. A. M. Almas (2003). "Damage Detection in structures from mode Shape to frequency response function methods".Mechanical Systems and Signal Processing,17(3): pp. 489-498.

[6] H.Y. Hwang, C. Kim (2004). "Damage detection in structures using a few frequency response measurements". Journal of Sound and Vibration. 270: pp.1-14.
[7] X. Liu, N.A.J.Lieven and P.J.Escamilla-Ambrosio (2009). "Frequency response function shape-based methods for structural damage localization". Mechanical Systems and Signal Processing 23: pp.1243-1259.

[8] D.P. Patil., S.K. Maiti (2005). "Experimental verification of a method of detection of multiple cracks in beams based on frequency measurements". Journal of Sound and Vibration, 281: pp. 439-451.

[9] Suresh, N. (2013), "Fire Resistance of Steel Structure", Built Expressions, Vol. 2(5), pp. 56-64.

[10] Ou, Li and Duan (editors), (2006)," Structural Health Monitoring and Intelligent Infrastructure". ISBN 0415 39652 2. Taylor and Francis Group., London.

[11] Purkiss J.A, (2009), "Fire Safety Engineering: Design of Structures", Second Edition, ButterworthHeinemann, An imprint of Elsevier, ISBN: 978-81-3122008-5.

[12] ANSYS Release 14.5, ANSYS Inc., 2012. 